\title{
Physicochemical Properties of Diacetylenic Light Fuel Oil from Congolese Oleaginous Plant Ongokea gore (Hua) Pierre
}

\author{
J. K. Ntumba, ${ }^{1}$ A. Mulula, ${ }^{1}$ K. T. Kashishi, ${ }^{1}$ M. N. Mifundu, ${ }^{1}$ R. Robiette, ${ }^{2}$ and K. M. Taba ${ }^{1}$ \\ ${ }^{1}$ Department of Chemistry, Faculty of Sciences, University of Kinshasa, BP 190, Kinshasa XI, Congo \\ ${ }^{2}$ Institute of Condensed Matter and Nanosciences, Université Catholique de Louvain, Place Louis Pasteur 1 Box L4.01.02, \\ 1348 Louvain-la-Neuve, Belgium
}

Correspondence should be addressed to J. K. Ntumba; joekanko@gmail.com

Received 8 November 2016; Revised 12 January 2017; Accepted 5 February 2017; Published 2 March 2017

Academic Editor: Luqman Chuah Abdullah

Copyright (C) 2017 J. K. Ntumba et al. This is an open access article distributed under the Creative Commons Attribution License, which permits unrestricted use, distribution, and reproduction in any medium, provided the original work is properly cited.

\begin{abstract}
Vegetable oil-based fuels are promising alternative fuels for diesel and light fuel engines because of their environmental and economic strategic advantages. In this study, Ongokea gore oil (OGO) and its fully hydrogenated oil were transesterified by means of ethanol in the presence of sodium ethoxide. Fatty acid ethyl esters (FAEE) products were confirmed by ${ }^{1} \mathrm{H}$ NMR and characterized by physical-chemical methods in accordance with the ASTM D 6751 and AFNOR M 15-009 specifications for biodiesels and light biofuels. These methods concern determination of color, density, viscosity, flash and pour points, ash, water and sulfur contents, and corrosion on copper. It was found that pure fatty acid ethyl esters of Ongokea gore oil (B100) and its hydrogenated oil (B100$\mathrm{H}$ ) meet standard requirements for most of the biodiesel characteristics studied. Only the kinematic viscosity and density values were outside recommended biodiesel standard limits which makes them unsuitable for use in diesel engines. In accordance with the AFNOR M 15-009 specifications of light fuels, they can be used in light fuel engines. Physical-chemical properties of B20, a FAEE blend in petrodiesel, are within the limits prescribed for petrodiesel standards. In brief, Ongokea gore seeds, a nonedible and high-oil-producing feedstock, are suitable starting material for production of light biofuel. The latter blends in petrodiesel can be used as fuel in diesel engines.
\end{abstract}

\section{Introduction}

Vegetable oils are considered as a long-term promising source of renewable energy because of their potential to solve problems of environmental safety caused by constant dependence of the world on fossil fuels [1-9]. Commonly used fossil fuels such as oil, coal, and natural gas are associated with negative impacts on environment, particularly on global warming [1012]. In addition, the supply of these nonrenewable energy resources is likely to end in a near future [13-15]. Therefore, the search for renewable energy resources, such as vegetable oils, is strongly encouraged. It was reported that, in diesel engines, vegetable oils can be used directly as a fuel or as a mixture with petrodiesel [16, 17]. Nevertheless, their high viscosity and low fuel atomization in engines lead to an inaccurate fuel-air mixing and inefficient combustion [1821]. Problem occurs also during the coking in the injector, deposits in the engine, and thickening lubricants during prolonged operating of the engine [22, 23]. Hence, prior to their use as biodiesel, these vegetable oils have to be subjected to a pretreatment, such as transesterification with short alcohols [24-27].

In a previous study, we have shown that seeds of Ongokea gore (Hua) Pierre, which contain about $55 \%$ of oil (also called isano oil), possess interesting sustainable chemical applications [28]. Major fatty acids in O. gore oil contain diacetylenic groups such as isanic acid, bolekic acid, 8hydroxy-octadeca-13,17-diene-9,11-diynoic acid, 8-hydroxyoctadec-13-ene-9,11-diynoic acid, and octadeca-13,17-diene9,11-diynoic acid.

Nowadays, the $O$. gore oil has limited application and the natural production of seeds remains underutilized. To the best of our knowledge, there is no report on production of biofuel using isano oil. In this study, O. gore oil has been used as a potential source of starting material for light biofuel production. Therefore, we set to prepare fatty acid ethyl ester 
(FAEE) of both O. gore oil and its fully hydrogenated oil. Their physicochemical properties have been analyzed according to ASTM D 6751 and AFNOR M 15-009 specifications and their potential use as biofuel in diesel or light fuel engine evaluated. A FAEE blend in petrodiesel, B20 (20:80 mixed), has been also prepared and evaluated.

\section{Materials and Methods}

2.1. Materials. Adam's catalyst $\left(\mathrm{PtO}_{2} \cdot \mathrm{H}_{2} \mathrm{O}\right)$ and sodium ethoxide ( $\mathrm{NaOEt}$ ) were purchased from Acros and were used without further purification. Analytical grade solvents, ethyl acetate and ethanol, were purchased from VWR.

Dried seeds of $O$. gore were collected from the Eala botanical garden in Mbandaka, Democratic Republic of Congo (DRC). The material was authenticated at the herbarium of INERA (Institut National de Recherches Agronomiques), Department of Biology, Faculty of Sciences, University of Kinshasa, DRC.

\subsection{Methods}

2.2.1. Extraction of Oil. The oil was obtained from dehulled and milled seeds by solvent extraction process (maceration), using cyclohexane as solvent at room temperature for $48 \mathrm{~h}$, followed by filtration. After filtration, the solvent was removed in a rotary evaporator, to give $55 \%$ of a yellow oil.

2.2.2. Hydrogenation of Isano Oil [31]. Isano oil ( $0.15 \mathrm{gr})$ and Adam's catalyst ( $5 \mathrm{~mol} \%$ ) were mixed in ethyl acetate $(50 \mathrm{~mL})$. The reaction mixture was purged twice with argon and then 3 times with hydrogen. The mixture was then stirred at room temperature for 48 hours under hydrogen atmosphere (double balloon, $1 \mathrm{~atm}$ ) and then filtered through celite before being concentrated in a rotary evaporator. A white powder was obtained with a quantitative yield.

2.2.3. Preparation of Ethyl Esters of Isano Oil. Synthesis of ethyl ester of isano oil was carried out by transesterification with sodium ethoxide according to the method of Christie [32]. In a $1 \mathrm{~L}$ round-balloon flask (immersed in a temperature controlling silicon oil bath, equipped with a magnetic stirrer, a thermometer, and a condenser with a balloon filled of helium) containing a known amount of ethanol (6:1 molar ratio to oil), isano oil and then sodium ethoxide ( $6: 1$ molar ratio to oil) were added. The reaction mixture was stirred vigorously and heated at $70^{\circ} \mathrm{C}$ for $1 \mathrm{~h}$. Upon cooling, it separated into two layers. The ester mixture formed the upper layer and glycerin formed the lower layer. Excess ethanol from upper layer was recovered, using a rotary evaporator. Ethyl acetate $(30 \mathrm{~mL})$ was then added to the residue, and the resulting solution was washed with water and neutralized with few drops of aqueous $\mathrm{HCl} 1 \mathrm{~N}$ followed by extraction with ethyl acetate (three times). The organic extracts were dried over anhydrous magnesium sulfate, and the solvent was removed under reduced pressure.

The hydrogenated isano oil fatty acid ethyl ester was prepared following similar procedure. Isano oil and its hydrogenated oil fatty acid ethyl ester were named B100 and
B100-H, respectively. For comparison purpose, a mixture of $80 \%$ of fossil fuel diesel and $20 \%$ of B100 was prepared; the latter was called B20.

Proton Nuclear Magnetic Resonance analysis of B100 and B100-H ( ${ }^{1} \mathrm{H}$ NMR) was carried out to confirm that the above hydrogenation and transesterification reactions took place. ${ }^{1} \mathrm{H}$ NMR analysis was recorded on NMR Bruker Avance $500 \mathrm{MHz}$ spectrometers. The chemical shifts were reported in ppm downfield from internal tetramethylsilane (TMS) at $\delta=0$.

The physicochemical properties of different fuels obtained were determined at the SEP-Congo Society (Kinshasa, D.R. Congo). The physicochemical properties determined according to international standards ASTM D 6751 [33] and AFNOR M 15-009 [29] are color (ASTM D-1500), density (ASTM D-4052), viscosity at $37.8^{\circ} \mathrm{C}$ and $40^{\circ} \mathrm{C}$ (ASTM D-445), viscosity at $50^{\circ} \mathrm{C}$ (NF T 60-100), flash point (ASTM D-93), pour point (ASTM D-97), ash content (ASTM D-482), water content (ASTM D-95), sulfur content (ASTM D-4294), and copper corrosion (ASTM D-130).

\section{Results and Discussion}

3.1. Transesterification of Oil to FAEE. ${ }^{1} \mathrm{H}$ NMR spectrum of the $\alpha$-methylene groups of the long-chain ethyl esters should present a signal in the region between 4.00 and $4.40 \mathrm{ppm}$ as quadruplet (characteristic of ethyl esters), while the spectrum of oils showed signals associated with the $\alpha$-methylene groups of the triacylglycerides (doublet of doublets) [33].

3.1.1. Production of B100. Transesterification process yielded about $80 \%$ of Isano oil's FAEE which was attested by a quadruplet at $4.13 \mathrm{ppm}{ }^{1} \mathrm{H} \mathrm{NMR}$, due to methylene hydrogens of the ethyl carbon (C1) neighbors oxygen of the ester (Figure 1(b)). Isano oil's ${ }^{1} \mathrm{H}$ NMR spectrum exhibited signals at $4.14 \mathrm{ppm}$ and $4.30 \mathrm{ppm}$ due to two glycerol hydrogen atoms (Figure 1(a)).

3.1.2. Production of B100- $H$. The effectiveness of the oil hydrogenation reaction was confirmed by comparing ${ }^{1} \mathrm{H}$ NMR spectra prior to hydrogenation (Figure 1(a)) and after hydrogenation of isano oil (Figure 2).

Vinylic hydrogen atoms located in the region between 4.5 and 6.5 ppm in isano oil's ${ }^{1} \mathrm{H}$ NMR (Figure 1(a)) disappeared in the ${ }^{1} \mathrm{H}$ NMR of the hydrogenated product. Only signals due to the protons of the central glycerol part of tri-, di-, and monoglycerides present in the oil remained (Figure 2).

All triglycerides were converted to ethyl esters. Comparing ${ }^{1} \mathrm{H}$ NMR spectra before and after transesterification of hydrogenated oil (Figures 2 and 3, resp.), one can notice multiplets corresponding to glycerol hydrogen in the region between 4.00 and $4.30 \mathrm{ppm}$ which changed to a quadruplet after reaction in the same region, corresponding to ethyl hydrogen atoms of methylene neighboring oxygen. The presence of signals at $3.55 \mathrm{ppm}, 3.66 \mathrm{ppm}$, and $5.30 \mathrm{ppm}$ (central hydrogen atoms of the glycerol part) could be due to the presence of mono- and/or diglycerides which would be still present in the obtained product. 


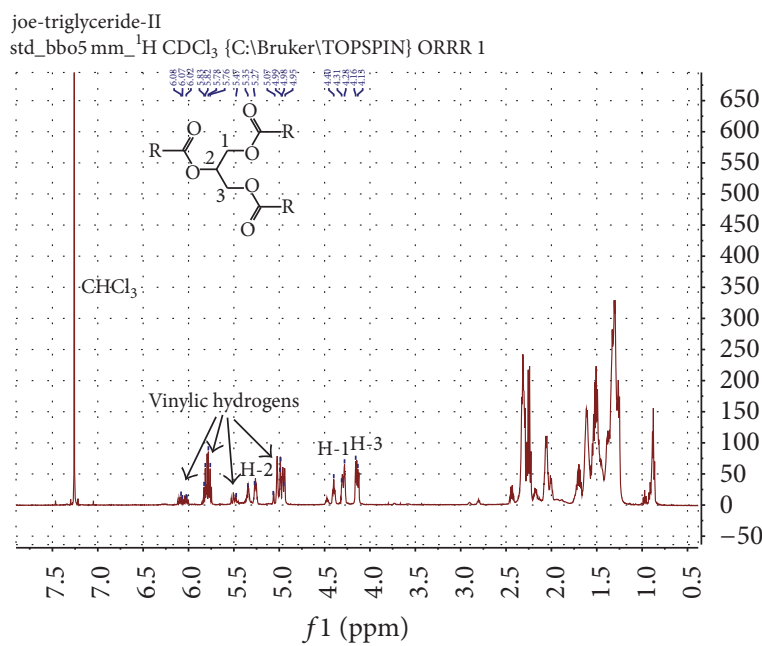

(a)

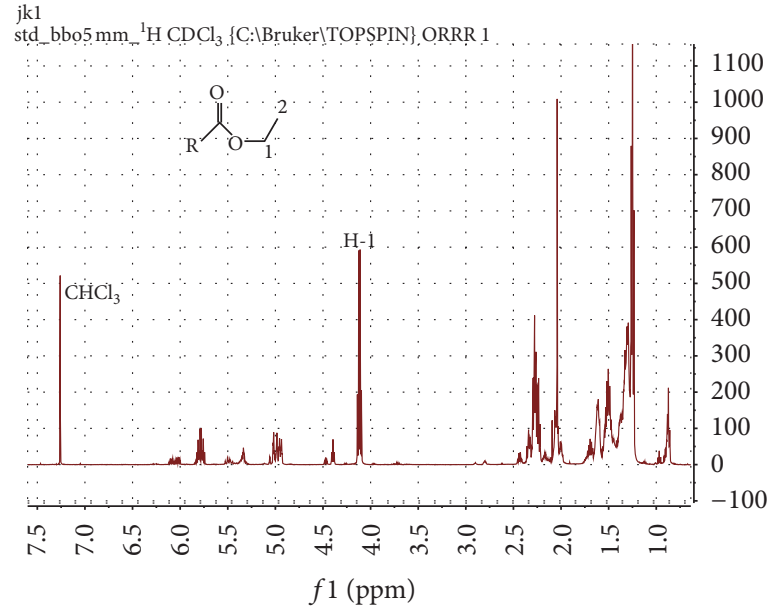

(b)

FIgURE 1: ${ }^{1} \mathrm{H}$ NMR: (a) of isano oil and (b) of ethyl ester from isano oil.

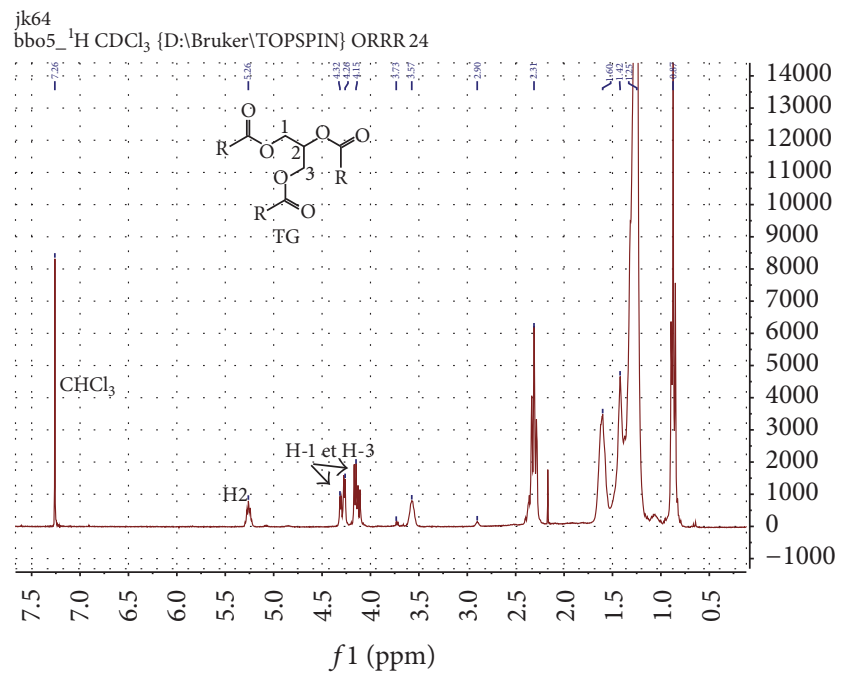

FIGURE 2: ${ }^{1}$ HNMR of hydrogenated isano oil. TG: triglyceride.

3.2. Fuel Characterization. The samples were tested to determine the fuel characteristics according to ASTM D 6751 and AFNOR M 15-009 Biodiesel and Light fuel oil Quality Assurance Standard Test. Table 1 summarizes the test methods used, the standards limit as recommended by ASTM D 6751 and AFNOR M 15-009, and our results.

Color has no direct influence on functioning of an engine but just gives an indication of the quality of samples. Indeed, for diesel, the color shows the quality of cracking during the refining of crude oil; it indicates trace pollution from black asphalt products [34]. For vegetable oils, color is due to either the presence of suspended solids or the presence of the pigments that contain oils such as $\beta$-carotene.

The density is a basic physical property which can be used (in addition to other properties) to characterize the light and heavy fractions of a fuel. A density in the range

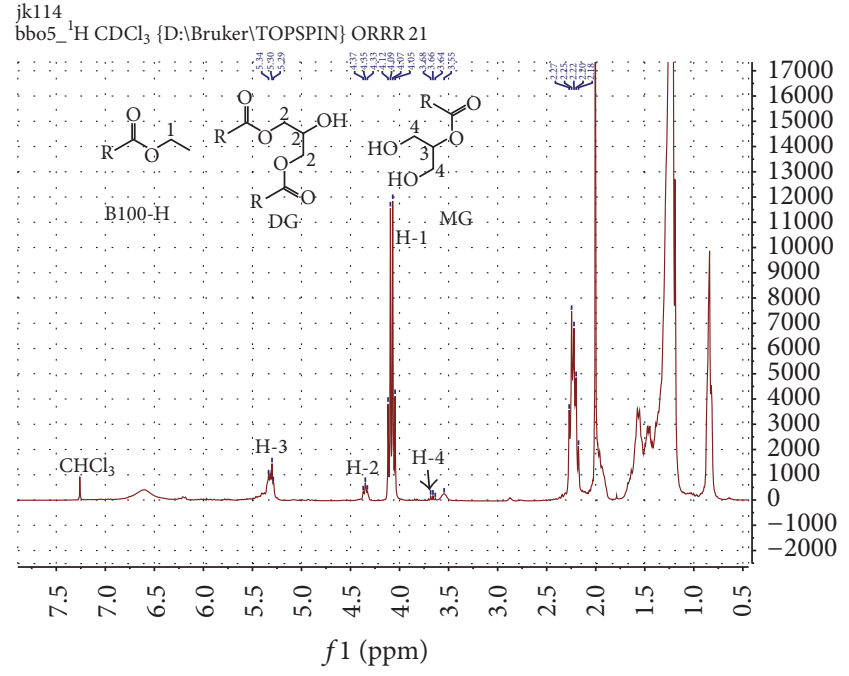

Figure 3: ${ }^{1} \mathrm{HNMR}$ of B100-H. DG: diglyceride; MG: monoglyceride.

$810<d<890 \mathrm{Kg} / \mathrm{m}^{3}$ ensures good running of engine [34]. In view of our results, Ongokea gore oil (OGO), its FAEE $\mathrm{B} 100$, and its hydrogenated oil FAEE B100-H have all densities beyond the maximum limit required of $890 \mathrm{Kg} / \mathrm{m}^{3}$. In their study on ethanolysis of Waste Cooking Oil Ethyl Esters of olive and sunflower oils, Encinar et al. found that the density of FAEE obtained was in accordance with limitation standards [35]. B20 (80\% fossil fuel diesel) has logically a lower mass than O. Gore oil, B100 and B100-H, and hence a lower density $\left(865 \mathrm{~kg} / \mathrm{m}^{3}\right)$. Since a too dense fuel tends to deplete the fuel mixture in the combustion chamber due to poor fuel atomization by the injectors, causing an increase in particulate emissions (unburned) O. gore oil, B100 and B100$\mathrm{H}$ products, will have bigger risk of impoverishment of their fuel mixture as compared to B20 and diesel. 
TABle 1: Physicochemical properties of GO, OGO, B100, B100-H, and B20.

\begin{tabular}{|c|c|c|c|c|c|c|c|}
\hline Properties (units) & Limitations & $\begin{array}{c}\text { Gasoil } \\
\text { (GO) }\end{array}$ & $\begin{array}{c}\text { Ongokea } \\
\text { gore oil } \\
(\mathrm{OGO})\end{array}$ & B100 & $\mathrm{B} 100-\mathrm{H}$ & B20 & $\begin{array}{c}\text { Methods } \\
{[29,30]}\end{array}$ \\
\hline Yield (\%) & - & - & 55 & 80 & 80 & 100 & - \\
\hline Color (code) & $5,0 \max$ & 4,0 & 4,0 & 4,0 & 4,0 & 4,0 & $\begin{array}{l}\text { ASTM } \\
\text { D-1500 }\end{array}$ \\
\hline Density at $15^{\circ} \mathrm{C}\left(\mathrm{Kg} / \mathrm{m}^{3}\right)$ & $810,0-890,0$ & 867,0 & 965,0 & 943,0 & 928,0 & 865,9 & $\begin{array}{l}\text { ASTM } \\
\text { D-4052 }\end{array}$ \\
\hline Viscosity at $37,8^{\circ} \mathrm{C}\left(\mathrm{mm}^{2} / \mathrm{s}\right.$ oucSt $)$ & $2,0-6,0$ & 4,11 & - & - & - & 5,30 & ASTM D-445 \\
\hline Viscosity at $40^{\circ} \mathrm{C}\left(\mathrm{mm}^{2} / \mathrm{s}\right.$ oucSt $)$ & $2,0-6,0$ & 4,09 & - & - & - & 5,22 & ASTM D-445 \\
\hline Viscosity at $50^{\circ} \mathrm{C}\left(\mathrm{mm}^{2} / \mathrm{s}\right.$ or cSt $)$ & $\leq 15$ & - & - & 4,5 & 3,2 & - & $\begin{array}{c}\text { AFNOR } \\
\text { NF T } 60-100\end{array}$ \\
\hline Flash point $\left({ }^{\circ} \mathrm{C}\right)$ & $60 \mathrm{~min}$ & 73 & 102 & 88 & 79 & 64 & $\begin{array}{c}\text { ASTM } \\
\text { D-93 }\end{array}$ \\
\hline Pour point $\left({ }^{\circ} \mathrm{C}\right)$ & $+5 \max$ & -10 & -31 & -25 & -1 & -13 & ASTM D-97 \\
\hline Total sulfur (\% weight) & $0,5 \max$ & 0,219 & 0,025 & 0,022 & 0,025 & 0,140 & $\begin{array}{c}\text { ASTM } \\
\text { D-4294 }\end{array}$ \\
\hline Ash contents (\% masse) & $0,01 \max$ & 0,01 & 0,0031 & 0,0198 & 0,012 & 0,0161 & ASTM D-482 \\
\hline Water content ( $\%$ vol) & $0,05 \max$ & 0,0 & 0,4 & 0,0 & 0,4 & 0,08 & $\begin{array}{l}\text { ASTM } \\
\text { D-95 }\end{array}$ \\
\hline Corrosion of $\mathrm{Cu}$ (code) & $1 \max$ & la & la & la & 1a & la & $\begin{array}{l}\text { ASTM } \\
\text { D-130 }\end{array}$ \\
\hline
\end{tabular}

One of the properties to be considered in assessing the overall risk of a fuel flammability is the flash point. This is the highest temperature at which a fuel can be handled without risk of explosion [36]. The flash point is much higher for starting raw oil $\left(102^{\circ} \mathrm{C}\right)$. Other less dense products have lighter constituents than those of the oil. Thus, their vapor pressure is higher, making their flashpoint lower $(88,79$, and $64^{\circ} \mathrm{C}$, corresponding to $\mathrm{B} 100, \mathrm{~B} 100-\mathrm{H}$, and $\mathrm{B} 20$, resp.). However, the flash point observed for $\mathrm{B} 100, \mathrm{~B} 100-\mathrm{H}$, and B20 (Table 1) meets the ASTM specifications for all biodiesel products. So, as a fuel, they are all expected to be safe during transport and storage.

The pour point of a fuel is the lowest temperature at which fuel freezes. In other words, this is an index of the lowest temperature of its use for certain applications. This value determines the fuel heating conditions to consider in cold weather by appropriate additives [34]. Ongokea gore oil is more viscous; thus, it should freeze much slower $\left(-31^{\circ} \mathrm{C}\right)$ than its corresponding ethyl esters B100 and B100-H $(-25$ and $-1^{\circ} \mathrm{C}$, resp.), which are more fluid. B20 also presents a lower pour point than Ongokea gore oil $\left(-13^{\circ} \mathrm{C}\right)$. This latter was not purified before use; it thus may be possible that a high content of heavy fraction is responsible for its high viscosity and therefore its high pour point. Maximum permitted sulfur content is fixed at $0.5 \%$ by weight. Sulfur compounds are known to cause corrosion of shirts diesel engines and foul odors of diesel exhausts. The use of sulfuric acid in the preparation of biodiesel by acid catalysis may cause, in the case of a noneffective elimination of the acid, deterioration of rubber components and corrosion of parts of metal engine. A base catalysis is therefore recommended.
The ash components are considered as undesirable impurities or contaminants. These are salts and inorganic oxides that remain in the solid state after complete combustion of the fuel: among them, silicon, iron, calcium, sodium, and vanadium, with the latter representing, in some cases, $50 \%$ of the total ash [34]. The specifications provide no measurable traces of ash in the fuel to avoid solid deposits on the cold parts such as valves. In this study, the ash content is within acceptable standards for all tested products.

In itself, water would not be a drawback but it usually contains either dissolved or suspended inorganic matter which may give ash, especially sodium and magnesium chlorides. The water content is thus set to no measurable traces. Moreover, the purification of heavy fuels can be achieved by stirring with water, which dissolves the soluble inorganic matter, followed by centrifugation, which removes the contaminated water and solids suspension [34]. However, in the case of biodiesel, which are ethyl esters, it would be better not to have any water because the presence of residual base or acid would hydrolyze esters into carboxylic acids which undoubtedly wear engine gaskets. A measurable amount of water content was detected in the Ongokea gore oil $(0.4 \%)$, in $\mathrm{B} 100-\mathrm{H}(0.4 \%)$, and in $\mathrm{B} 20(0.08 \%)$. These values are slightly above the required standard of $0.05 \%$, which would be due to poor drying after aqueous workup during preparation of these fuels.

Corrosion is, with rust, one of the phenomena that lead to an increase in wear and, in extreme cases, to the destruction of certain parts of the machines. Corrosion is caused by the attack of metals by acidic compounds. In diesel engines, these compounds are sulfurous and sulfuric anhydride and sulfuric 
acid derived from the oxidation of the engine oil or fuel [36]. The test of corrosion on the blade copper is used to control the corrosiveness of fuel toward the copper metal, which is used in diesel engines. According to the standard method, corrosion should not exceed level 1 (light yellow) in a reference scale. In this study, all biodiesels and crude oil have the maximum recommended value of 1 . They do not corrode the engine neither during operation nor during storage.

Viscosity was performed at different temperatures: at $37.8^{\circ} \mathrm{C}$ for conforming to national standards, at $40^{\circ} \mathrm{C}$ for conforming to ASTM D 445 requirement for diesel fuel oil grade D2, and at $50^{\circ} \mathrm{C}$ for conforming to ASTM D 445 for diesel fuel oil grade D4 or light fuel oil.

The kinematic viscosity of $\mathrm{B} 20$ is 5.30 centistokes at $37.8^{\circ} \mathrm{C}$ and 5.22 at $40^{\circ} \mathrm{C}$. These values are slightly higher than that of diesel fuel at the same temperature, but this is without harmful consequences to the engine because the value obtained is found to be within acceptable limits (26 cSt). Regarding Ongokea gore oil, B100, and $\mathrm{B} 100-\mathrm{H}$, their viscosities at $37.8^{\circ} \mathrm{C}$ or $40^{\circ} \mathrm{C}$ were not carried to completion because, after 30 minutes of evaluation, analysis was not over, while it took only about 5 minutes for diesel. Obviously, the mobility of the particles is smaller in B100 and B100$\mathrm{H}$ as compared to diesel explaining the lower fluidity and the increase in viscosity. However, this increase makes more difficult fuel atomization and reduces the effectiveness of injectors [34]. These viscosity values obtained certify that FAEE B100 and B100-H have an adverse flow and spray quality for diesel engine and therefore a poor quality of spontaneous combustion. We thus proposed to measure the viscosities of these standard FAEE at $50^{\circ} \mathrm{C}$, comparing them to light fuel oil. Indeed, according to French 7 standards AFNOR [30], a light fuel oil is a mixture of hydrocarbons from mineral or synthetic origin, particularly destined for the production of heat in the combustion plants and meeting the following specifications:

(i) Distillation: distillate volume $<65 \%$ at $250^{\circ} \mathrm{C}$ and $<85 \%$ at $350^{\circ} \mathrm{C}$

(ii) Viscosity $\leq 15 \mathrm{cSt}$ at $50^{\circ} \mathrm{C}$

(iii) Sulfur content $\leq 2 \%(\mathrm{w} / \mathrm{w})$

(iv) Water content $\leq 0.5 \%(\mathrm{w} / \mathrm{w})$

(v) Flash point $\geq 70^{\circ} \mathrm{C}$

(vi) Pour point $\leq 0^{\circ} \mathrm{C}$.

Thus, B100 and $\mathrm{B} 100-\mathrm{H}$ whose viscosities are above $15 \mathrm{cSt}$ at either $37.8^{\circ} \mathrm{C}$ or $40^{\circ} \mathrm{C}$ and 4.5 and 3.2 centistokes, respectively, at $50^{\circ} \mathrm{C}$ are good alternative light fuel oil instead of diesel.

In general, the behavior observed in this work, in relation to color, flash and pour points, ash, water and sulfur contents, and corrosion on copper, agrees with that obtained by other authors $[35,37,38]$.

\section{Conclusion}

This study elaborates the use of underutilized, nonedible $O$. gore oil as a starting biomaterial for the production of a high quality light fuel oil.

Two different FAEE (fatty acid ethyl esters) and one biodiesel were prepared and analyzed: O. gore oil (B100), a biofuel obtained by ethanolic transesterification, B100$\mathrm{H}$, which is a biofuel produced by transesterification of hydrogenated isano oil, and B20, a mixture of $20 \%$ B100 and $80 \%$ diesel. These three biofuels have been subjected to physicochemical tests according to international standards ASTM and AFNOR. It should be noted that B20 biodiesel is a fuel of high quality able to replace diesel in a diesel engine because all its physicochemical properties studied (color, density, viscosity, flash point, pour point, ash content, water content, sulfur content, and corrosion on $\mathrm{Cu}$ ) are in the range of required standards. Since fuel physicochemical properties of $\mathrm{B} 100$ and $\mathrm{B} 100-\mathrm{H}$ are of the same order, it is likely that $\mathrm{B} 100-\mathrm{H}$ will be more stable during storage. Both fuels are not effective biodiesels candidate but they can be used as light fuel oil. Thus, FAEE of Ongokea gore oil appears to be promising alternative fuel for conventional light biofuel engines. The production of $O$. gore light fuel oil could be an added value to an underutilized agricultural product.

\section{Competing Interests}

The authors declare that they have no competing interests.

\section{Acknowledgments}

This work was funded by the Commission Universitaire pour le Développement (CUD). This work was conducted in part in Belgium at the Université catholique de Louvain. R. Robiette is a Chercheur Qualifié of the Fonds de la Recherche Scientifique (FNRS).

\section{References}

[1] J. Xue, T. E. Grift, and A. C. Hansen, "Effect of biodiesel on engine performances and emissions," Renewable and Sustainable Energy Reviews, vol. 15, no. 2, pp. 1098-1116, 2011.

[2] L. Li and B. P. Loo, "Alternative and transitional energy sources for urban transportation," Current Sustainable/Renewable Energy Reports, vol. 1, no. 1, pp. 19-26, 2014.

[3] L. Lin, Z. Cunshan, S. Vittayapadung, S. Xiangqian, and D. Mingdong, "Opportunities and challenges for biodiesel fuel," Applied Energy, vol. 88, no. 4, pp. 1020-1031, 2011.

[4] R. Altin, S. Çetinkaya, and H. S. Yücesu, "Potential of using vegetable oil fuels as fuel for diesel engines," Energy Conversion and Management, vol. 42, no. 5, pp. 529-538, 2001.

[5] A. S. Ramadhas, S. Jayaraj, and C. Muraleedharan, "Use of vegetable oils as I.C. engine fuels-a review," Renewable Energy, vol. 29, no. 5, pp. 727-742, 2004.

[6] S. S. Sidibé, J. Blin, G. Vaitilingom, and Y. Azoumah, "Use of crude filtered vegetable oil as a fuel in diesel engines state of the art: literature review," Renewable and Sustainable Energy Reviews, vol. 14, no. 9, pp. 2748-2759, 2010. 
[7] A. B. Chhetri, M. S. Tango, S. M. Budge, K. C. Watts, and M. R. Islam, "Non-edible plant oils as new sources for biodiesel production," International Journal of Molecular Sciences, vol. 9, no. 2, pp. 169-180, 2008.

[8] S. P. Singh and D. Singh, "Biodiesel production through the use of different sources and characterization of oils and their esters as the substitute of diesel: a review," Renewable and Sustainable Energy Reviews, vol. 14, no. 1, pp. 200-216, 2010.

[9] A. Demirbas, "Progress and recent trends in biodiesel fuels," Energy Conversion and Management, vol. 50, no. 1, pp. 14-34, 2009.

[10] T. F. Stocker, D. Qin, G. K. Plattner, M. Tignor, S. K. Allen, and P. M. Midgley, "Climate change Lecture: The physical science basis," 2014.

[11] M. Höök and X. Tang, "Depletion of fossil fuels and anthropogenic climate change-a review," Energy Policy, vol. 52, pp. 797-809, 2013.

[12] R. J. Plevin, M. O'Hare, A. D. Jones, M. S. Torn, and H. K. Gibbs, "Greenhouse gas emissions from biofuels' indirect land use change are uncertain but may be much greater than previously estimated," Environmental Science and Technology, vol. 44, no. 21, pp. 8015-8021, 2010.

[13] R. E. Dunlap and A. K. Jorgenson, The Wiley-Blackwell Encyclopedia of Globalization, Edited by G. Ritzer, Wiley-Blackwell, 1st edition, 2012.

[14] B. R. Singh and O. Singh, "Global trends of fossil fuel reserves and climate change in the 21st century," in Fossil Fuel and the Environment, S. Khan, Ed., chapter 8, InTech, Rijeka, Croatia, 2012.

[15] H. Pan, Y.-S. Hu, and L. Chen, "Room-temperature stationary sodium-ion batteries for large-scale electric energy storage," Energy and Environmental Science, vol. 6, no. 8, pp. 2338-2360, 2013.

[16] A. Murugesan, C. Umarani, R. Subramanian, and N. Nedunchezhian, "Bio-diesel as an alternative fuel for diesel engines-a review," Renewable and Sustainable Energy Reviews, vol. 13, no. 3, pp. 653-662, 2009.

[17] N. Tippayawong, A. Pittayapak, and W. Jompakdee, "Analysis of energy requirement for vegetable oil production in Northern Thailand's farms," CMU Journal, vol. 2, pp. 37-47, 2003.

[18] J. Blin, C. Brunschwig, A. Chapuis et al., "Characteristics of vegetable oils for use as fuel in stationary diesel enginestowards specifications for a standard in West Africa," Renewable and Sustainable Energy Reviews, vol. 22, pp. 580-597, 2013.

[19] A. S. Ramadhas, S. Jayaraj, and C. Muraleedharan, "Use of vegetable oils as I.C. engine fuels-a review," Renewable Energy, vol. 30, pp. 795-803, 2005.

[20] K. Pramanik, "Properties and use of jatropha curcas oil and diesel fuel blends in compression ignition engine," Renewable Energy, vol. 28, no. 2, pp. 239-248, 2003.

[21] A. Srivastava and R. Prasad, "Triglycerides-based diesel fuels," Renewable \& Sustainable Energy Reviews, vol. 4, no. 2, pp. 111133, 2000.

[22] W. M. Adaileh and K. S. AlQdah, "Performance of diesel engine fuelled by a biodiesel extracted from a waste cocking oil," Energy Procedia, vol. 18, pp. 1317-1334, 2012.

[23] T. P. Durrett, C. Benning, and J. Ohlrogge, "Plant triacylglycerols as feedstocks for the production of biofuels," Plant Journal, vol. 54, no. 4, pp. 593-607, 2008.

[24] M. K. Lam, K. T. Lee, and A. R. Mohamed, "Homogeneous, heterogeneous and enzymatic catalysis for transesterification of high free fatty acid oil (waste cooking oil) to biodiesel: a review," Biotechnology Advances, vol. 28, no. 4, pp. 500-518, 2010.

[25] I. M. Atadashi, M. K. Aroua, A. R. A. Aziz, and N. M. N. Sulaiman, "Refining technologies for the purification of crude biodiesel," Applied Energy, vol. 88, no. 12, pp. 4239-4251, 2011.

[26] J. Zhang, S. Chen, R. Yang, and Y. Yan, "Biodiesel production from vegetable oil using heterogenous acid and alkali catalyst," Fuel, vol. 89, no. 10, pp. 2939-2944, 2010.

[27] A. P. Vyas, J. L. Verma, and N. Subrahmanyam, "A review on FAME production processes," Fuel, vol. 89, no. 1, pp. 1-9, 2010.

[28] J. K. Ntumba, L. Collard, K. M. Taba, and R. Robiette, "Isolation of a series of fatty acid components of ongokea gore seed (isano) oil and their detailed structural analysis," Lipids, vol. 50, no. 3, pp. 313-322, 2015.

[29] Annual Book of ASTM Standards, Petroleum Products, Lubricants, and Fossil Fuels, section 5, ASTM International Press, Pennsylvania, Pa, USA, 2010.

[30] AFNOR: Recueil des Normes Françaises, Produits Pétroliers: Combustibles Liquides, AFNOR Press, Paris, France, 7th edition, 1988.

[31] B. M. Trost, M. J. Bartlett, A. H. Weiss, A. J. Vonwangelin, and V. S. Chan, "Development of Zn-prophenol-catalyzed asymmetric alkyne addition: synthesis of chiral propargylic alcohols," Chemistry - A European Journal, vol. 18, no. 51, pp. 16498-16509, 2012.

[32] W. W. Christie, "Preparation of ester derivatives of fatty acids for chromatographic analysis," in Advances in Lipid MethodologyTwo, W. W. Christie, Ed., Oily Press, Dundee, UK, 1993.

[33] I. G. Rosset, M. C. H. Tavares, E. M. Assaf, and A. L. M. Porto, "Catalytic ethanolysis of soybean oil with immobilized lipase from Candida antarctica and ${ }^{1} \mathrm{H}$ NMR and GC quantification of the ethyl esters (biodiesel) produced," Applied Catalysis A: General, vol. 392, no. 1-2, pp. 136-142, 2011.

[34] P. Wuithier, Le pétrole: Raffinage et Génie Chimique, Editions Technip, Paris, France, 1st edition, 1965.

[35] J. M. Encinar, J. F. González, and A. Rodríguez-Reinares, "Ethanolysis of used frying oil. Biodiesel preparation and characterization," Fuel Processing Technology, vol. 88, no. 5, pp. 513-522, 2007.

[36] J. Denis, J. Briant, and J. C. Hipeaux, Physico-Chimie des Lubrifiants, Analyses et Essais, Editions Technip, Paris, France, 1997.

[37] N. Foidl, G. Foidl, M. Sanchez, M. Mittelbach, and S. Hackel, "Jatropha curcas L. as a source for the production of biofuel in Nicaragua," Bioresource Technology, vol. 58, no. 1, pp. 77-82, 1996.

[38] L. R. V. Da Conceição, C. E. F. Da Costa, G. N. Da Rocha Filho, E. R. Pereira-Filhob, and J. R. Zamian, "Ethanolysis optimisation of jupati (Raphia taedigera Mart.) oil to biodiesel using response surface methodology," Journal of the Brazilian Chemical Society, vol. 26, no. 7, pp. 1321-1330, 2015. 

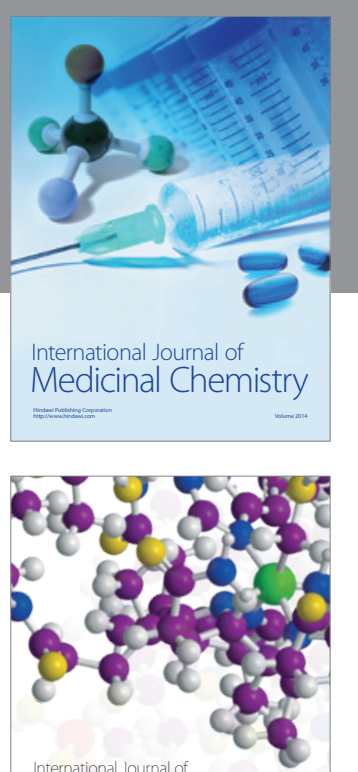

Carbohydrate Chemistry

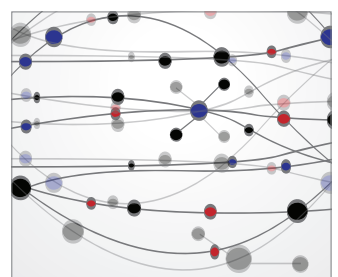

The Scientific World Journal
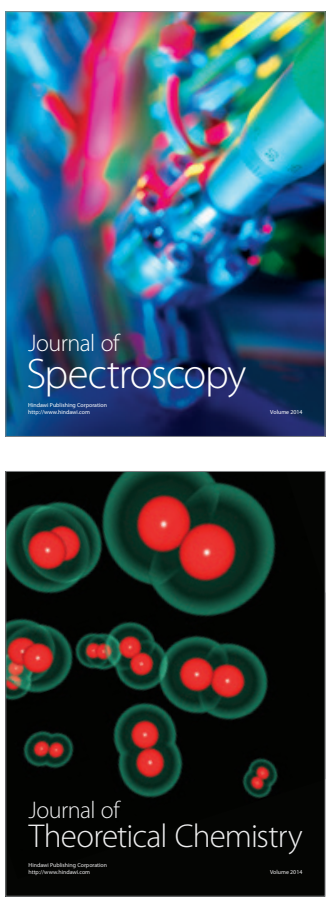
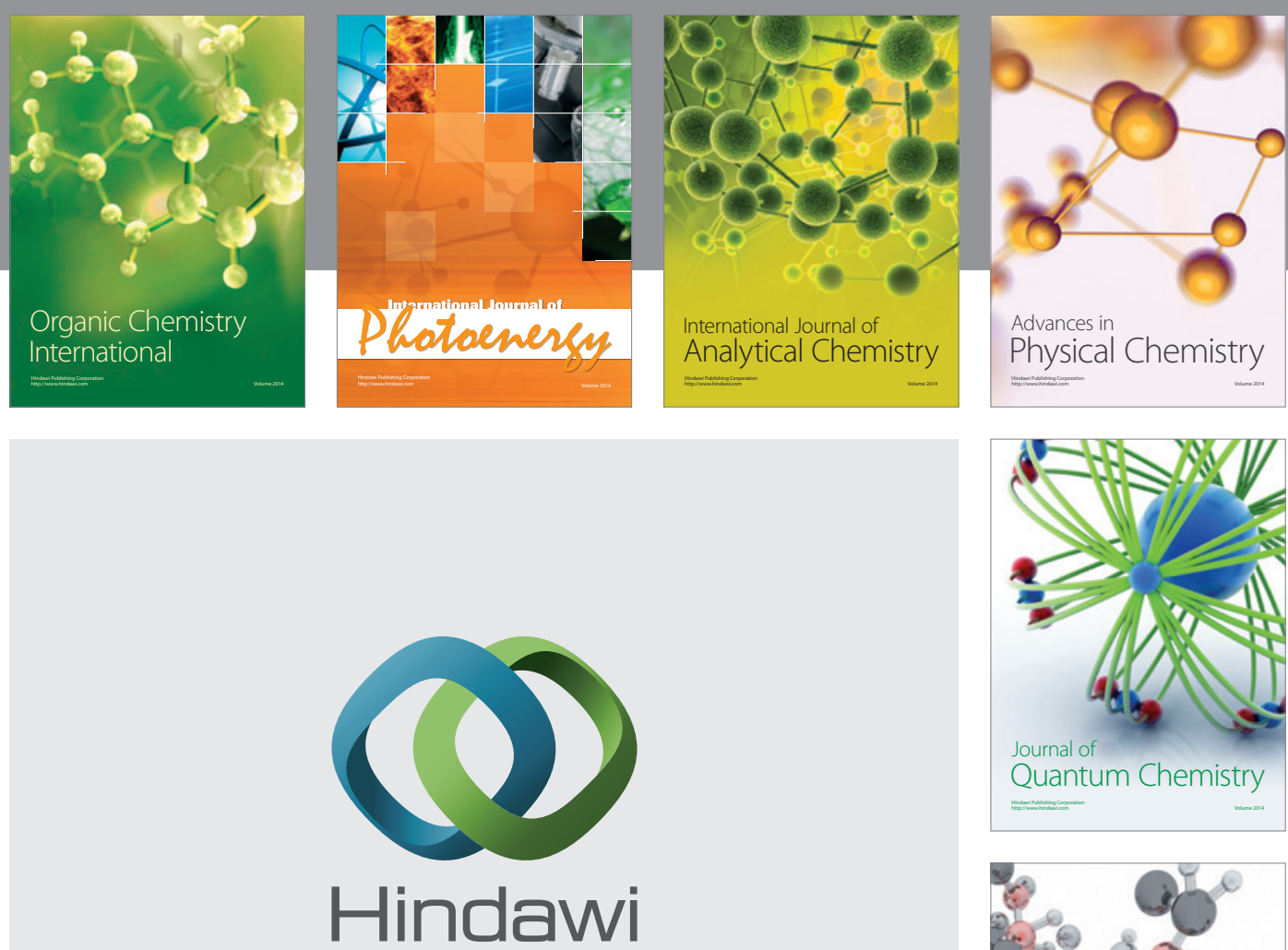

Submit your manuscripts at

https://www.hindawi.com

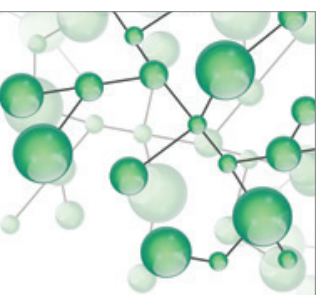

International Journal of

Inorganic Chemistry
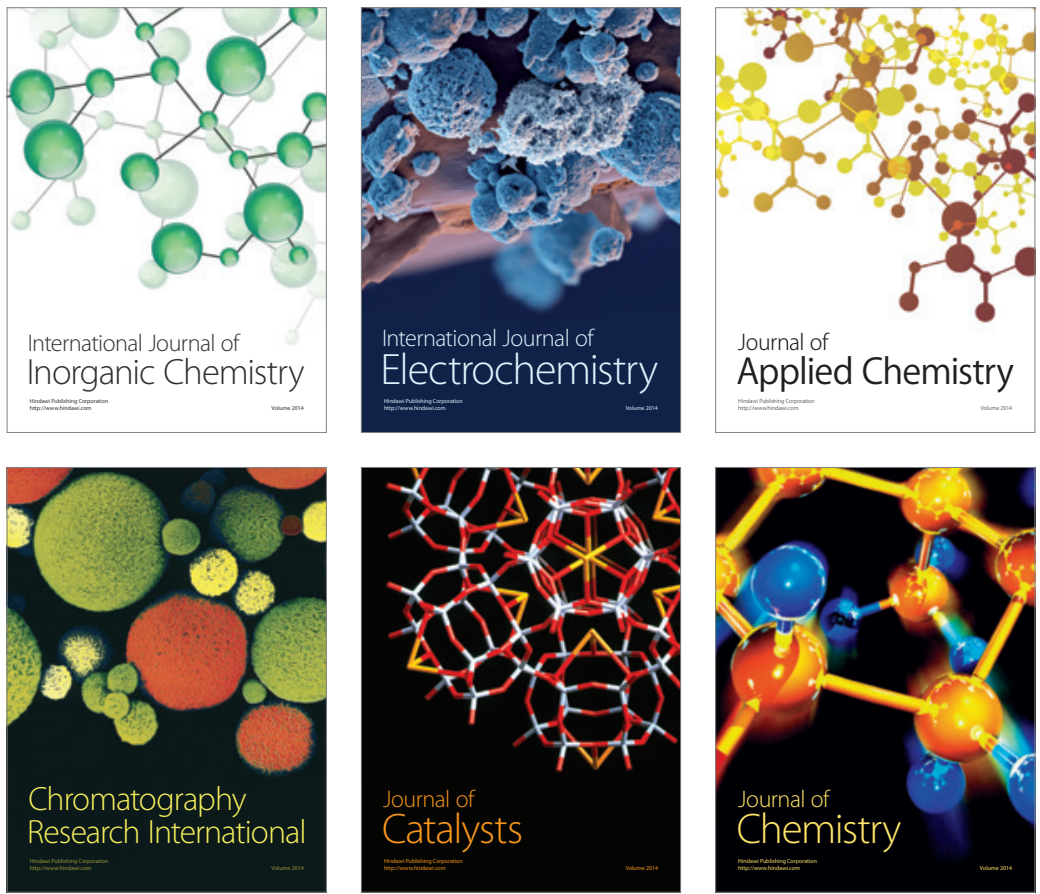

Journal of

Applied Chemistry
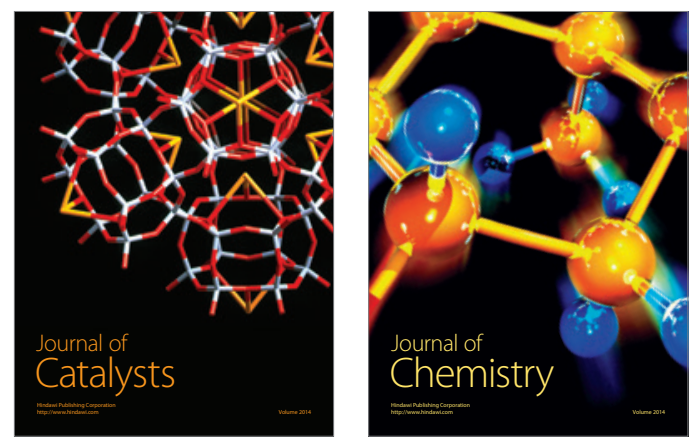
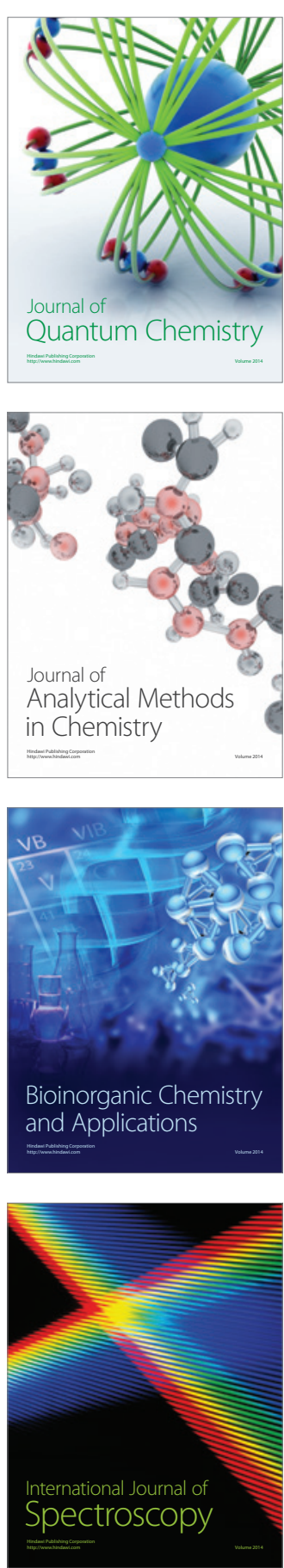